\title{
Identificação de impurezas e misturas em pó de café por meio de comportamento espectral e análise de imagens digitais ${ }^{(1)}$
}

\author{
Eduardo Delgado Assad(2), Edson Eyji Sano(2), Silvia Aida Rodrigues da Cunha ${ }^{(3)}$, \\ Tânia Barreto Simões Correa ${ }^{(4)}$ e Hilda Rosa Rodrigues ${ }^{(4)}$
}

\begin{abstract}
Resumo - Para eliminar divergências na interpretação dos resultados e agilizar os atuais métodos de detecção de fraudes em café torrado e moído, foi estabelecido um método baseado na análise por imagem e fundamentado no princípio de que diferentes materiais de origem orgânica, como o pó de café, podem apresentar reflectâncias distintas em diferentes comprimentos de onda do espectro eletromagnético. Partiu-se da hipótese de que o pó de café adulterado, quando submetido a uma fonte artificial de iluminação, apresenta uma reflectância, nos canais vermelho (R), verde (G) e azul (B), diferente em relação à do pó de café não-adulterado. Após as etapas de limpeza, secagem e homogeneização, foram geradas imagens multiespectrais das amostras de café, por meio de uma lupa acoplada a uma câmara CCD (Charge Coupled Device). A quantificação das impurezas na amostra foi obtida utilizando-se curvas de calibração entre a área relativa obtida pela classificação supervisionada de imagens e a porcentagem de impurezas presentes nas amostras. Esse novo método permite agilidade da resposta, ausência de subjetividade nos resultados e não-destruição das amostras analisadas, e assegura um patamar mínimo de detecção de $95 \%$ das impurezas do produto.
\end{abstract}

Termos para indexação: café, pó, adulteração, controle de qualidade, espectrometria.

\section{Identifying adulteration in coffee powders by spectral signatures and digital analyses}

Abstract - In order to reduce divergences in the interpretation of the results obtained by current methods of fraud detection in powdered coffees, a new method to quantify coffee adulterants is presented in this study. This method is based on image analyses and on the principle that different organic materials found in ground coffees present distinct spectral signatures. The hypothesis is that the adultered coffees, when submitted to an artificial source of illumination, present different reflectance values in RGB (Red/Green/Blue) channels in comparison to those from pure coffees. After the cleaning, drying, and homogenization steps, multispectral images of coffee samples were generated by using a glass magnifier connected to a CCD (Charge Coupled Device) camera. The images were stored and classified by means of a digital image software. The spectral signatures of each component in the coffee sample were identified from their histograms in percentage, and the amounts (by weight) of adulterants in the coffee sample were obtained by calibration curves. The advantages of this method are the capability to analyse a great number of samples in a relatively short time period, the lack of subjectivity in the results, and the non destruction of the coffee samples. This method reaches a minimum accuracy of $95 \%$ in the quantification of adulteration in the powdered coffee.

Index terms: coffee, powders, adulteration, quality controls, spectrometry.

(1) Aceito para publicação em 7 de maio de 2001 .

(2) Embrapa-Centro de Pesquisa Agropecuária dos Cerrados (CPAC), Br $020 \mathrm{Km} \mathrm{18,} \mathrm{CEP} \mathrm{73301-970} \mathrm{Planaltina,} \mathrm{DF}$ E-mail: assad@cpac.embrapa.br, sano@cpac.embrapa.br

(3) Embrapa-CPAC. Bolsista do Funcafé.

E-mail: silvia@cpac.embrapa.br

(4) Embrapa-Centro Nacional de Pesquisa de Tecnologia Agroindustrial de Alimentos, Av. das Américas, 29501, CEP 23020-470 Guaratiba, RJ.

E-mail: tania@ctaa.embrapa.br, hilda@ctaa.embrapa.br

\section{Introdução}

A detecção de impurezas e misturas no pó de café torrado e moído é uma preocupação constante no que diz respeito principalmente à garantia da qualidade do produto. Por fraude, considera-se a mistura, intencional ou não, de materiais estranhos ao produto, normalmente de baixo custo, que alteram a sua qualidade e causam danos ao consumidor, especialmente, os de ordem econômica. 
No Brasil, as impurezas ou misturas encontradas, com maior freqüência, no café torrado e moído são cascas e paus, milho, cevada, triguilho, açúcar mascavo e soja, entre outras. Um dos principais problemas encontrados na identificação dessas substâncias refere-se aos métodos analíticos empregados, pois são demorados, subjetivos e apresentam resultados muitas vezes discordantes.

Com relação ao café torrado e moído, por exemplo, o processo convencionalmente utilizado consiste na preparação de lâminas microscópicas e na sua análise visual. As lâminas são preparadas com reagentes químicos, e a quantificação das impurezas é baseada na comparação do porcentual do extrato aquoso da amostra que está sendo analisada, com o do extrato aquoso do café puro (Menezes Júnior \& Bicudo, 1958). Essa técnica de quantificação apresenta algumas desvantagens, pois além do fato de os reagentes químicos destruírem a amostra, existem situações em que a porcentagem do extrato aquoso da amostra sob análise pode situar-se abaixo do valor predeterminado para o café puro. Isto acontece, por exemplo, quando o café está misturado com soja. Além disso, por tratar-se de análise microscópica, este processo constitui-se em um método subjetivo e, conseqüentemente, a confiabilidade dos resultados é pequena, já que depende da experiência do analista e, por isso, está sujeita a erros humanos, além de ser demorado e oneroso.

Utilizando-se os princípios físicos do sensoriamento remoto (Becker, 1979; Novo, 1988) é possível determinar algumas características do comportamento espectral de amostras de um alvo. Considerando-se que uma amostra de pó de café, torrado e moído, possui uma certa similaridade com uma amostra de solo peneirado, é possível avaliar o comportamento espectral desse pó, assim como se faz com solos. Madeira Netto (1996) mostrou como diversos componentes mineralógicos de um solo podem ter seu comportamento detectado, utilizando-se os princípios da reflexão difusa. Assim, se um solo apresentar como componente somente quartzo, ele terá um tipo de comportamento; à medida que se encontram novos componentes, como goetita, hematita ou gibsita, este comportamento vai se alterando, sendo possível identificar por espectrorradiometria, a influência desses componentes no comportamento do solo.
No caso do pó de café, partiu-se do mesmo princípio. Uma amostra de café puro tem um determinado tipo de comportamento espectral. Ao se adicionar outros materiais, esse comportamento espectral começa a se alterar, sendo possível identificar, por reflectância, a influência do material adicionado na curva espectral do material original. Uma vez identificada essa influência, pode-se utilizar radiômetros de banda larga (câmaras CCD - Charge Coupled Device, por exemplo) para captação e posterior classificação de imagens.

Os métodos até hoje desenvolvidos e que utilizam uma câmara CCD para captação de imagem procuram classificar e padronizar grãos, separar fisicamente as impurezas, e identificar metais pesados nos grãos; ou seja, esses métodos têm como objetivo caracterizar determinado padrão de forma e cor. Alguns autores têm utilizado as faixas espectrais do infravermelho próximo (Downey \& Boussion, 1996; Downey \& Spengler, 1996) e infravermelho médio (Kemsley et al., 1995; Suchánek et al., 1996; Downey et al., 1997), em questões associadas à fraude de café, mas somente para identificar misturas entre diferentes variedades de café (arábica e robusta). A principal desvantagem das técnicas que utilizam as faixas do infravermelho está no custo elevado da aquisição dos instrumentos.

Este trabalho teve como principais objetivos construir curvas espectrais do pó de café torrado e moído, puro e com diferentes concentrações de impurezas e misturas, verificar se as curvas espectrais se diferenciam ao longo do espectro visível, classificar as imagens captadas nos canais vermelho (R), verde (G) e azul (B) de uma câmara CCD, para quantificar as impurezas e misturas adicionadas ao pó de café puro, e estabelecer curvas de calibração entre a quantidade de impurezas ou misturas classificadas e o seu porcentual em peso adicionado ao pó de café.

\section{Material e Métodos}

O método, desenvolvido pela Embrapa-Centro de Pesquisa Agropecuária dos Cerrados, em Brasília, DF, e pela Embrapa-Centro Nacional de Pesquisa de Tecnologia Agroindustrial de Alimentos, no Rio de Janeiro, RJ, baseia-se no princípio físico de que diferentes materiais apresentam reflectâncias distintas em diferentes comprimentos de onda do espectro eletromagnético. Assim, partiu-se 
da hipótese de que o pó de café adulterado, sendo submetido a uma fonte artificial de iluminação, teria uma reflectância nos canais $\mathrm{R}, \mathrm{G}$ e B diferente da reflectância do pó de café puro.

Para verificar essa hipótese, foram preparadas amostras de pó de café torrado e moído, adulteradas artificialmente, no laboratório da ABIC (Associação Brasileira da Indústria do Café), com porcentuais conhecidos de cascas, paus e milho, nas seguintes concentrações: $1 \%, 2 \%, 3 \%$, $4 \%, 5 \%, 10 \%, 20 \%, 30 \%, 40 \%$ e $50 \%$. Foi utilizado o ponto de torra escura, que representa mais de $90 \%$ do café comercializado no Brasil.

Inicialmente, cada amostra do pó de café, com aproximadamente $3 \mathrm{~g}$, foi homogeneizada, lavada e filtrada em papel de filtragem rápida, com $90 \mathrm{~mL}$ de clorofórmio, com a finalidade de desengordurar o pó de café e desagregar as partículas de impurezas ou misturas que venham junto com o pó.

Após a filtragem, o material é secado ao ar por quatro horas, e passado numa peneira de 50 mesh. A seguir o pó é colocado numa placa de Petri de $4 \mathrm{~cm}$ de diâmetro, com tampa, para se fazerem as medições e posterior reutilização.

Foi utilizado um espectrorradiômetro, marca GER MARK V (Signature user guide, 1995), com intervalos de comprimento de onda variando entre $310 \mathrm{~nm}$ e $2.550 \mathrm{~nm}$ e sensibilidade mínima de $5 \mathrm{~nm}$, para aquisição de medidas de reflectância das amostras de café. Antes de se fazer a medida, é feita uma calibração do aparelho numa placa de sulfato de bário, considerada como superfície perfeitamente refletora. Após a calibração, cada amostra é colocada no ponto de visada do espectrorradiômetro e medidos os valores de reflectância bidirecional.

Após a determinação das curvas de reflectância, as amostras foram levadas para um analisador de imagens, considerado como um radiômetro de banda larga. As imagens digitais das amostras puras e adulteradas de café foram captadas por uma câmara CCD (Charge Coupled Device), acoplada a uma lupa cuja ampliação ideal conseguida foi de 12 vezes. As imagens captadas foram transferidas para um analisador de imagens digitais e fez-se a medição da reflectância de cada amostra nas três bandas do azul (B), $\operatorname{verde}(G)$ e vermelho(R) do espectro visível. As imagens foram geradas no formato TIFF (Tagged Image File Format), e têm 480 pixels x 620 pixels. A transferência das imagens da lupa para o computador foi feita através de uma câmara de vídeo (CCD-IRIS/RGB Color Vídeo Câmera da Sony). $\mathrm{O}$ analisador de imagens utilizado foi o Kontron Imaging Systems KS-300 da Kontron Elektronik GmbH.

As imagens macroscópicas das amostras foram analisadas, identificando-se a resposta espectral de cada componente. Assim, o pó de café terá uma resposta variando de $X_{1}$ a $X_{n}$, e as impurezas "cascas e paus", variando de $Y_{1}$ a $Y_{n}$. A seguir, as imagens foram submetidas a uma classificação supervisionada por Máxima Verossimilhança (MAXVER), disponível no programa de processamento de imagens digitais SPRING, desenvolvido pelo Instituto Nacional de Pesquisas Espaciais (Câmara et al., 1996), de modo a identificar a quantidade de pixels que apresentam a mesma resposta espectral. Tais pixels são componentes de uma mesma classe, ou seja, a classe "cascas e paus", classe milho, classe sombra e a classe "pó de café". Feita esta identificação, por contagem de pixels, é possível conhecer a área de cada classe na imagem.

Conhecida a área de cada componente na imagem, são feitas as curvas de calibração entre a porcentagem da área na imagem e a porcentagem em peso da amostra, fraudada artificialmente. Para cada tipo de impureza e mistura foi estabelecida uma curva de calibração.

\section{Resultados e Discussão}

O primeiro resultado encontrado refere-se ao comportamento espectral das amostras de pó de café puro e mistura com diferentes impurezas, ou seja, cascas e paus. As cascas e paus são consideradas impurezas, pois parte-se do princípio de que vêm junto com o café em coco do terreiro de secagem, e portanto não são adicionadas intencionalmente ao pó de café, mas são torradas ao mesmo tempo. Quando a concentração de cascas e paus é grande, supõe-se que o pó de café seja fraudado intencionalmente. Analisando a curva espectral, observa-se que existe uma diferença de repostas entre os comprimentos de onda de 481 a $780 \mathrm{~nm}$ (Figura 1). No espectro do vermelho e infra-vermelho, as curvas se diferenciam bastante, sendo observadas as maiores reflectâncias nas amostras com $10 \%$ e $30 \%$ de impurezas. No entanto, tais curvas não foram incluídas neste estudo, pois a câmera CCD capta imagens apenas na faixa do visível.

No caso da análise referente a cascas e paus, é possível encontrar reflectâncias menores para concentrações maiores de impurezas, uma vez que, quando torradas, as cascas ficam mais escuras que os paus. Quando isto acontece, o comportamento espectral de uma amostra com concentração maior de cascas do que paus, pode ser diferente de uma com concentração menor de cascas do que de paus. O mais importante, neste caso, é ficar clara a diferença entre as curvas observadas do pó de café puro e 
do pó de café com impurezas. Esta diferença de reflectância mostra que é possível, mesmo utilizando bandas mais largas, classificar uma imagem, pois as respostas espectrais serão diferentes.

No caso do milho (considerado como mistura, pois é feito intencionalmente, ou seja, após a torra do café, este também é torrado e depois misturado ao pó), foi feita uma análise similar. As curvas de reflectância obtidas no espectro do visível evidenciam a diferenciação espectral a partir do comprimento de onda de $600 \mathrm{~nm}$. Nesse caso, como o milho torrado fica com cor mais escura que o café, este material absorve mais energia do espectro visível, obtendose reflectâncias menores. Assim, o café puro terá uma reflectância maior do que a do café com misturas. A curva do café puro é próxima do café com $30 \%$ de mistura, e mais afastada do café com $10 \%$ de mistura com milho (Figura 2). No caso do milho, existe uma relação inversa entre o aumento da reflectância e a concentração da mistura.

A separação de materiais por comportamento espectral reforça a hipótese de que uma imagem captada em comprimentos de onda diferente permitirá a classificação dos pixels, e, posteriormente, a quantificação de cada material na imagem. Para identificar os objetos que têm assinatura espectral diferente da do café na imagem captada, são coletados os valores digitais, codificados em 8 bits, de cada um.

Os valores da impureza "paus" são superiores aos valores do café e das cascas (Figura 3). As sombras constituem um dos componentes da imagem realçados após a extração com clorofórmio. Como o sistema de iluminação é lateral, sempre aparecerão

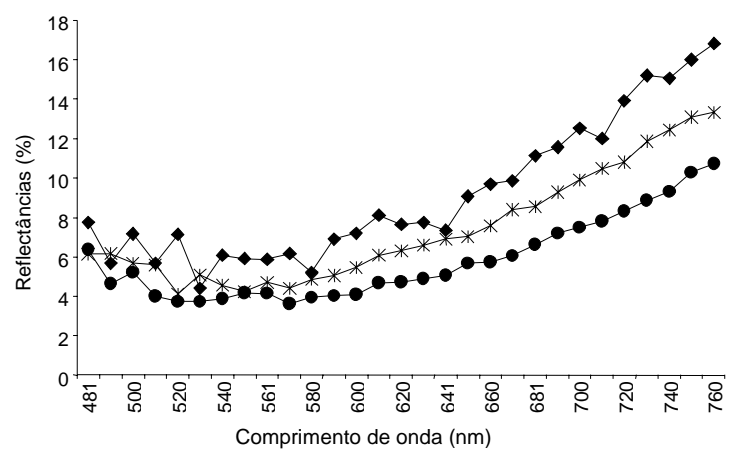

Figura 1. Curvas de reflectância do pó torrado e moído de café puro $(\diamond)$, com $10 \%(*)$ e $30 \%(\bullet)$ de cascas e paus. sombras nas imagens; portanto, esta classe deve ter sua área também quantificada. Os estudos radiométricos foram feitos para os comprimentos de onda variando de $481 \mathrm{~nm}$ a $780 \mathrm{~nm}$; assim, os valores digitais foram também coletados nos canais vermelho $(600 \mathrm{~nm}$ a $700 \mathrm{~nm})$, verde $(500 \mathrm{~nm}$ a $600 \mathrm{~nm})$ e azul $(400 \mathrm{~nm}$ a $500 \mathrm{~nm})$. No estudo radiométrico em questão, observou-se uma grande flutuação do sinal entre $400 \mathrm{~nm}$ e $500 \mathrm{~nm}$. Como o sinal captado pela câmera é uma banda larga e mais estável, a diferença de sinal existente entre os objetos da imagem é observada. As Figuras 4 e 5 ilustram as diferenças de valores digitais observados nas imagens capturadas pela câmera digital.

O resultado da classificação é a porcentagem de área ocupada por cada impureza na imagem analisada. Depois disso, é traçada uma curva de calibração

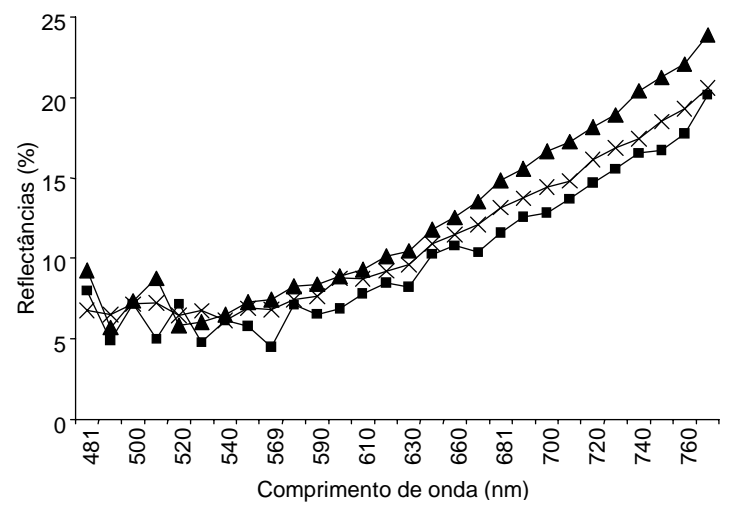

Figura 2. Curvas de reflectância do pó torrado e moído de café puro (ם), com $10 \%(\boldsymbol{\Delta})$ e com $30 \%(\times)$ de milho.

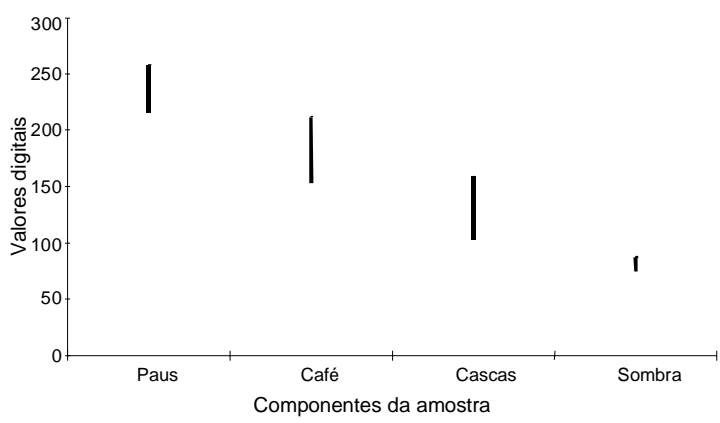

Figura 3. Valores digitais da imagem de café com cascas e paus no canal vermelho. 
relacionando o número de pixels encontrados na imagem e a impureza previamente conhecida na amostra. São ajustadas as equações de regressão entre o número de pixels e o porcentual de impureza para pó de café torrado e moído. Desta forma, uma amostra com $25 \%$ de cascas e paus, em peso, representa $55 \%$ da área classificada na imagem RGB (Figura 6). Com base nesta classificação, foi obtida a equação: $y=15,54 \ln x+5,44, \mathrm{R}^{2}=0,95$. Os valores de $x$ representam o porcentual de peso das cascas e paus (variável independente); os de $y$, o porcentual dessas impurezas na área classificada (variável dependente), e os de $\mathrm{R}^{2}$, os coeficientes de determinações entre as duas variáveis. Utilizando essa equação, é possível quantificar a porcentagem, em peso, das impurezas que foram identificadas numa amostra de café torrado e moído. Este método assegura um nível de detecção de fraudes com cascas e paus em cerca de $95 \%$.

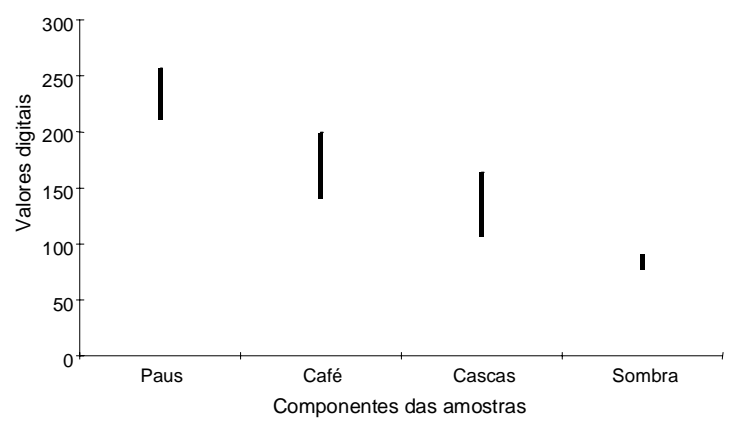

Figura 4. Valores digitais da imagem de café com cascas e paus no canal verde

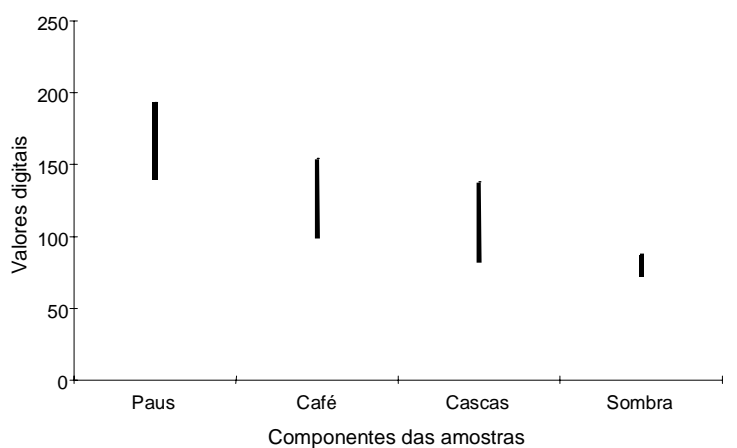

Figura 5. Valores digitais da imagem de café com cascas e paus no canal azul.
O mesmo procedimento foi adotado para as amostras de café com milho, ou seja, captaram-se as imagens RGB, e após a classificação quantificou-se o porcentual de milho que foi detectado. Construiuse, então, a curva de calibração, uma vez que se conhecia previamente o porcentual em peso que existia em cada amostra (Figura 7). Com base nesta classificação, foi obtida a equação: $y=0,55 x+0,26$, $\mathrm{R}^{2}=0,93$. Os valores de $x$ representam o porcentual de peso do componente milho (variável independente); os de $y$, o porcentual desta mistura na área classificada (variável dependente), e os de $\mathrm{R}^{2}$, os coeficientes de determinação entre as duas variáveis. Utilizando essa equação, é possível quantificar a porcentagem, em peso, da mistura que foi identificada numa amostra de café torrado e moído. Este método assegura um nível de detecção de fraudes com milho em cerca de $93 \%$. A adoção deste método, já em escala operacional, em que foram testadas 240 amostras de pó de café torrado e moído, permitiu quantificar o tempo necessário para execução da análise.

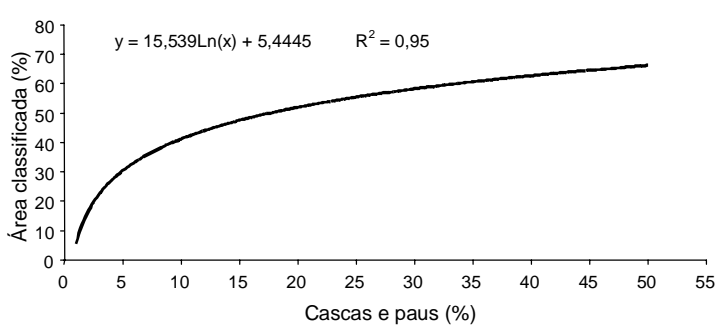

Figura 6. Relação entre a porcentagem de cascas e paus e da área classificada na imagem $R$ (vermelho), $G$ (verde) e B (azul)

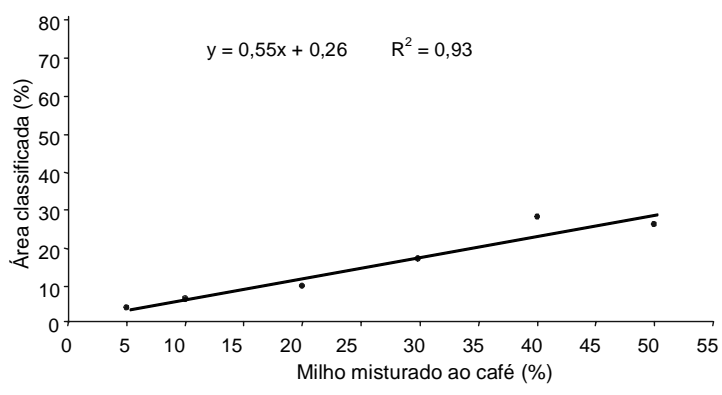

Figura 7. Relação entre a porcentagem de milho misturado no café e do porcentual da área classificada na imagem R (vermelho), G (verde) e B (azul). 
No caso da amostra pura, são necessários cerca de dois minutos para execução. No caso das amostras com impurezas, como são captadas seis imagens, são necessários 20 minutos para execução das análises das seis imagens.

\section{Conclusões}

1. A partir das curvas espectrais do pó de café torrado e moído, construídas entre os comprimentos de onda 481 e $780 \mathrm{~nm}$, a resposta espectral do café puro é maior que a do café adulterado com cascas e paus.

2. A partir das curvas espectrais do pó de café torrado e moído, construídas entre os comprimentos de onda 481 e $780 \mathrm{~nm}$, a resposta espectral do café puro é menor que a do café adulterado com milho, em diferentes concentrações.

3. As curvas espectrais, tanto para cascas e paus, quanto para o milho, têm a característica de maior diferenciação a partir do comprimento de onda do vermelho.

4. No caso do milho a relação entre a área das imagens captadas e a quantidade de impurezas é linear.

5. No caso de cascas e paus a relação entre a área das imagens captadas e a quantidade de impurezas é logarítmica.

\section{Agradecimentos}

À Associação Brasileira da Indústria do Café (ABIC) pelo fornecimento das amostras, orientação e importantes esclarecimentos feitos ao longo deste trabalho.

\section{Referências}

BECKER, F. Physique fondamentale de la télédétection In: BECKER F; BILLINGSLEY, F.; GOLDBERG, M.; HARALICK, R.; SAINT, G.; SCHANDA, E.; SCOTT, N.; TRAIZET, M.; VIEILLEFOSSE, M.; WATSON, K.
Principes physiques e mathématiques de la télédétection. Toulouse: Centre National d'Études Spatiales, 1979. p. 1-107.

CÂMARA, G.; FREITAS, U. M.; SOUZA, R. C. M.; GARRIDO, J. SPRING: integrating remote sensing and GIS by object-oriented data modeling. Computers \& Graphics, Oxford, v. 15, n. 6, p. 13-22, 1996

DOWNEY, G.; BOUSSION, J. Authentication of coffee bean variety by near-infrared reflectance spectroscopy of dried extract. Journal of the Science of Food and Agriculture, Chichester, v. 71, p. 41-49, 1996.

DOWNEY, G.; SPENGLER, B. Compositional analysis of coffee blends by near infrared spectroscopy. Irish Journal of Agricultural and Food Research, Dublin, v. 35 , p. $179-188,1996$

DOWNEY, G.; BRIANDET, R.; WILSON, R .H.; KEMSLEY, E. K. Near and mid-infrared spectroscopies in food authentication: coffee varietal identification. Journal of Agricultural and Food Chemistry, Washington, v. 45, n. 11, p. 4357-4361, 1997.

KEMSLEY, E. K.; RUAULT, S.; WILSON, R. H. Discrimination between Coffee arabica and Coffee canephora variant robusta beans using infrared spectroscopy. Food Chemistry, Oxford, v. 54, p. 321326, 1995

MADEIRA NETTO, J. S. Spectral reflectance properties of soils. Photo Interpretation, Paris, v. 2, p. 50-70, 1996

MENEZES JÚNIOR, J. B. F.; BICUDO, B. A. A. Sobre um método microscópico para contagem de cascas no café em pó. Revista do Instituto Adolfo Lutz, São Paulo, v. 11, p. 13-47, 1958.

NOVO, E. M. L. de M. Sensoriamento remoto: princípios e aplicações. 2. ed. São Paulo: E. Blücher, 1988. 308 p

SIGNATURE user guide: version 1.0. Millbrook: GER, 1995. $20 \mathrm{p}$

SUCHÁNEK, M.; FILIPOVA, H.; VOLKA, K.; DELGADILLO, I.; DAVIES, A. N. Qualitative analysis of green coffee by infrared spectroscopy. Journal of Analytical Chemistry, Moscow, v. 354, n. 3, p. 327-332, 1996. 